\title{
A STUDY OF THE ADSORPTION OF DYES FROM THEIR AQUEOUS SOLUTIONS BY MORUPULE COAL 1
}

\author{
M.S. Nadiye-Tabbiruka,Fortunate Phenyo Sejie, S.H.Coetzee and E.J. Salamula \\ Department of Chemistry, University of Botswana, Private bag 00704, Gaborone Botswana \\ nadiyemst@yahoo.com \\ Department of Chemistry, University of Botswana, Private bag 00704, Gaborone Botswana \\ fsejie@yahoo.com \\ Department of Physics, University of Botswana, Private bag 00704, Gaborone Botswana \\ 1.COETZEES@mopipi.ub.bw \\ ${ }^{3}$ Department of Chemistry, College of Math and Science, Makerere University \\ matsciejs@gmail.com
}

\section{ABSTRACT}

\begin{abstract}
AdsorptionofMethyl orange (MO) from its aqueous solution by steam activated Morupule coal was investigated spectrophotometrically using the batch technique and found to be reversible at all temperatures used. The effects of varying methyl orange concentration, $\mathrm{pH}$ and temperature were investigated. The adsorption rate and the adsorption capacity increased with increasing initial concentration, with decreasing solution $\mathrm{pH}$ and with increasing temperature. The adsorption capacity was found to be low probably due to the low coal surface area $\left(10 \mathrm{~m}^{2} \mathrm{~g}^{-1}\right)$. The increase in rate and capacity with increasing temperature is probably due to increased surface area originating from the swelling of coal, which results from heating. The adsorption kinetics fits the Lagergren pseudo second order model best thus the reaction is overall third order. Alternatively, the process could be two pseudo first order reactions occurring simultaneously. Results from the thermodynamic study fitted Freundlich model best indicating heterogeneity of the surface of the coal sample.
\end{abstract}

Keywords: Adsorption; Methyl orange; Morupule coal; kinetics; equilibrium.

\section{Academic Discipline And Sub-Disciplines}

Physical Chemistry; surface chemistry

\section{SUBJECT CLASSIFICATION}

Adsorption from solution

TYPE (METHOD/APPROACH)

Experimental investigation

\section{Council for Innovative Research}

Peer Review Research Publishing System

\section{Journal: Journal of Advances in Chemistry}

Vol. 11, No. 9

www.cirjac.com

editorjaconline@gmail.com, editor@cirjac.com 


\section{INTRODUCTION}

There are many water pollutants including radioactive isotopes, heavy metals, inorganic fertilisers and organic compounds from dying and printing textile industry and in research laboratories[1-4]. However, pollution of water by organic compounds is among the most serious health hazards even when present at low concentrations [5-8]. Water organic compounds' pollutants increase the development of antibiotic resistance of pathogens thus causing danger to the living systems [9, 10]. Chemical pollution of surface water presents a threat to the aquatic environment with hazardous effects such as genotoxicity, carcinogenicity, Neurotoxicity and disturbance to the energy transfer by lowering ATP production[11]. Coloured materials and organic dyes constitute the focus of many environmental concerns because of their nonbiodegradable and polluting nature [10, 12, 13].

Dyes are natural and synthetic coloured materials that are useful in a variety of industries [14-16]. Of these, Azo dyes are a class of synthetic organic dyes that contain the azo group $-\mathrm{N}=\mathrm{N}$ - in their molecular structure. These dyes are useful in several industries including food (Tartrazine, Yellow 2G, Sunset Yellow, Azorubine, Chrysoine resorcinol and Sunset Yellow FCF)[17]), textile (Dimethyl Fumarate (DMF), methyl orange, acid red (to mention but a few)[18] and laboratories (Methyl orange, methyl red, Chrysoine resorcinol [17, 19-22].

A variety of decontamination methods, including Coagulation, Flocculation, Ozonation, Reverse Osmosis, and adsorption, can be used to remove the above dyes as well as other water contaminants in purifying water. Among these, adsorption is one of the cheapest and most effective for removal of large soluble molecules from water. Therefore, it is widely used for the removal of organic compounds from polluted water [23]. Consequently, activated carbon is the most effective and commonly used adsorbent for decolourisation of water.

\section{EXPERIMENTAL}

\subsection{Materials}

\subsubsection{Preparation of the adsorbent}

Coal in form of lumps was collected from Morupule Colliery which is situated along Palapye-serowe road.

- Lumps were ground to a fine powder using a mortar and pestle. The powder was steam activated, allowed to cool in a desiccator until use. Fourier Transform Infra-Red (FTIR Perkin-Elmer) was used to identify the vibration frequency of the functional groups of the materials while Scanning Electron Microscope (SEM) was used to study the microstructure and morphology of the material

\subsubsection{Adsorbate}

Methyl Orange (Anionic, water soluble azo dye) powder $\left(\mathrm{C}_{14} \mathrm{H}_{14} \mathrm{~N}_{3} \mathrm{NaO}_{3} \mathrm{~S}\right.$, figure 1) supplied by SAARCHEM, South Africa was used without further purification. A solution of the dye was made by dissolving a known amount into double distilled de-ionised water. Other required dye concentrations were prepared by serial dilution. Several of these concentrations were used to obtain an absorbance vs concentration calibration curve at $\lambda=463 \mathrm{~nm}$ using a UVVisible spectrophotometer spectronic 20. This curve was used to obtain dye concentrations of experimental solutions.

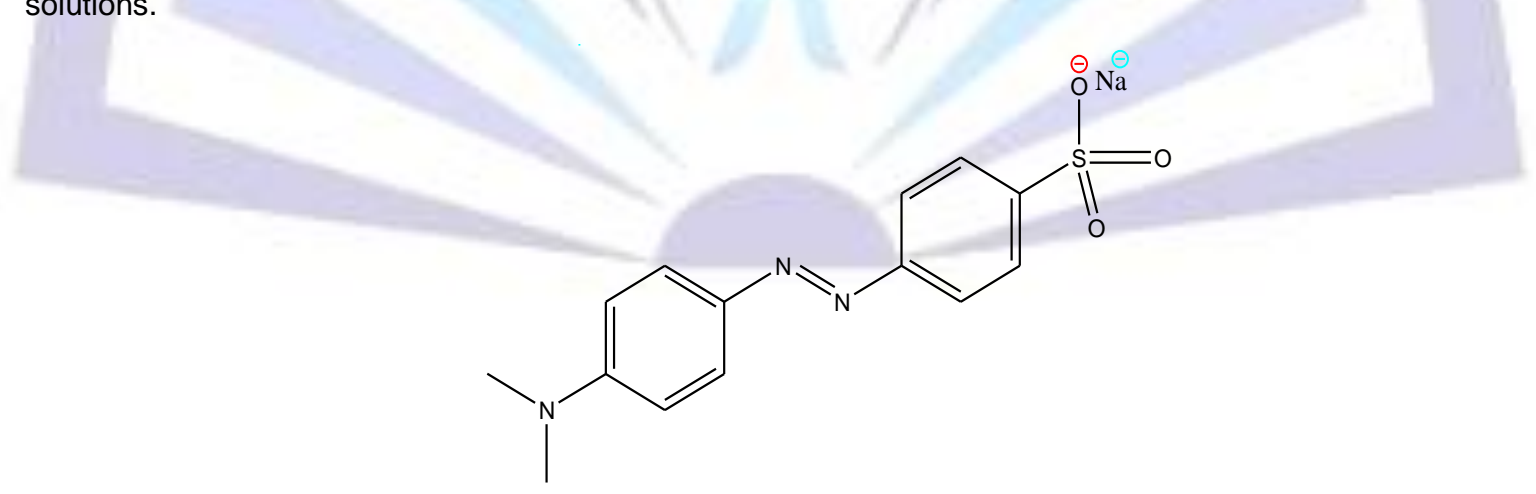

Figure 1structure of methyl orange

\subsection{Procedure}

\subsubsection{Adsorption Kinetics' studies}

$1.5 \mathrm{~g}$ of powdered coal was added to $150 \mathrm{ml}$ of $\mathrm{MO}$ solution in a screw capped bottle contained in a water bath at constant temperature and immediately a stop clock was started. Samples of the supernatant liquid were drawn off at predetermined time intervals, filtered using an appropriate filter paper and their absorbance were taken in a UV/VIS spectrophotometer at a wavelength of $463 \mathrm{~nm}$ to determine the current concentration. The amount adsorbed was obtained by difference from the 
initial concentrations and plotted against time (see Fig 4). This experiment was repeated for various MO concentrations, reaction temperature and $\mathrm{pH}$.

\subsubsection{Adsorption thermodynamics' studies}

In this section, a batch technique was used. MO $(1.5 \mathrm{~g})$ was added to each of several $250 \mathrm{~mL}$ screws capped bottles containing $150 \mathrm{ml}$ of methyl orange of varying initial concentrations. The bottles were kept in a thermostatic water bath shaker at a speed of $220 \mathrm{rpm}$ for $232 \mathrm{~min}$ at a constant temperature. After the samples had reached equilibrium, the solutions were filtered using $0.45 \mu \mathrm{m}$ filter paper and their residual concentrations were determined spectrophotometrically as before. The amount adsorbed at equilibrium, $\mathrm{q}_{\mathrm{e}}(\mathrm{mol} / \mathrm{g})$, was calculated by using equation 1 given below:

$Q_{e}=\frac{\left(C_{o}-C_{e}\right) * V(L)}{m(g)}$

Where $\mathrm{C}_{0}$ is the initial concentration of the dye and $\mathrm{C}_{e}$ is the equilibrium concentration (mol/L), $V(L)$ is the volume of methyl orange solution and $\mathrm{m}(\mathrm{g})$ is the weight of $\mathrm{MC}$. Equilibrium adsorption $\mathrm{Q}_{\mathrm{e}}$ values were used to plot an adsorption isotherm.

\subsubsection{Characterisation of the adsorbent}

Samples of coal were taken for scanning electron microscopy, and FTIR.

\subsection{RESULTS AND DISCUSSION}

\subsection{Characterisation of Adsorbents}

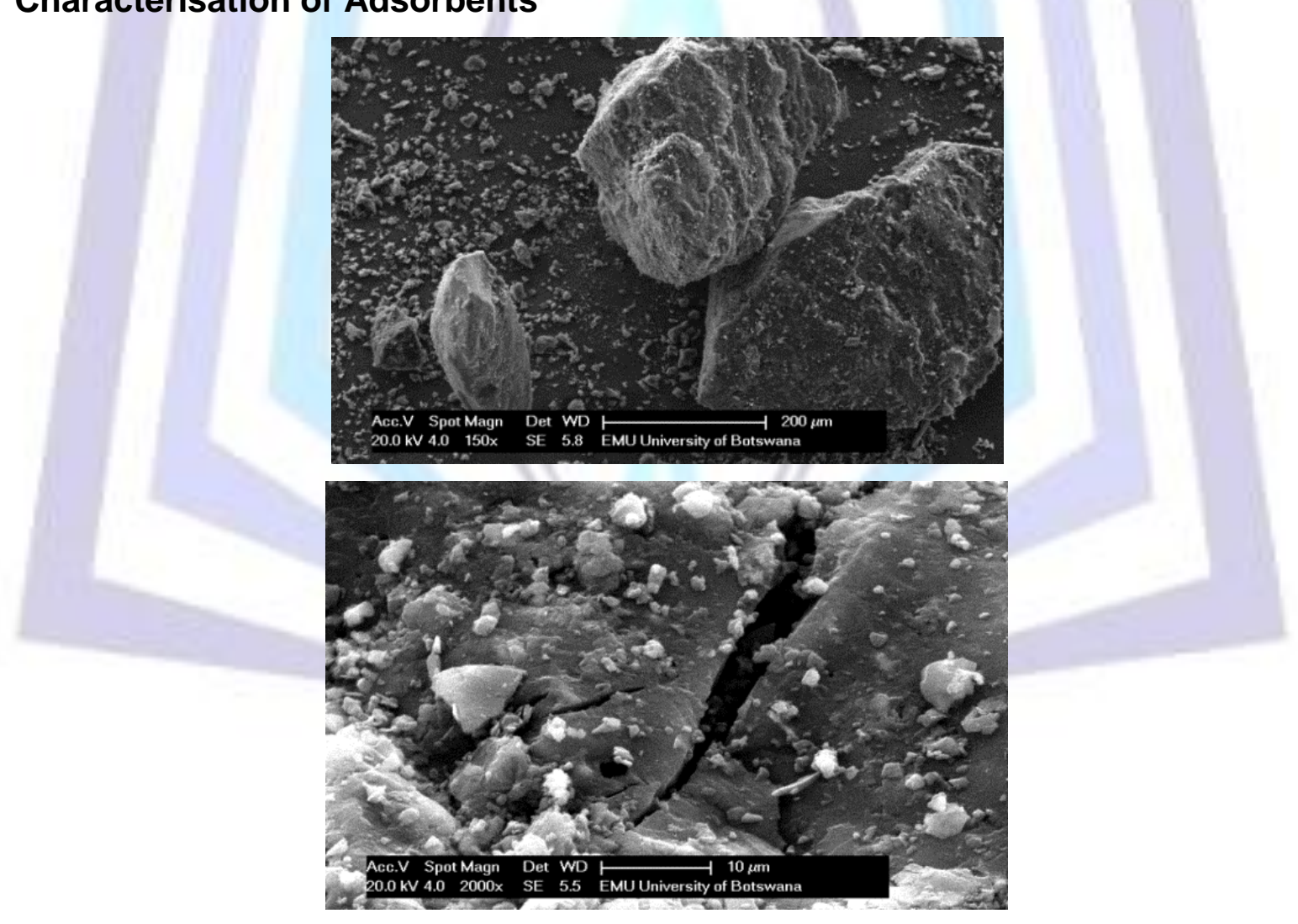

\section{Figure 2 Morupule coal Micrographs}

Figure 2 is a SEM microgram showing that Morupule coal is made up of small irregular, loose flakes. There are gaps in between the flakes, and this shows that the surface of Morupule coal is rough, irregular and nonporous, with cracks. 


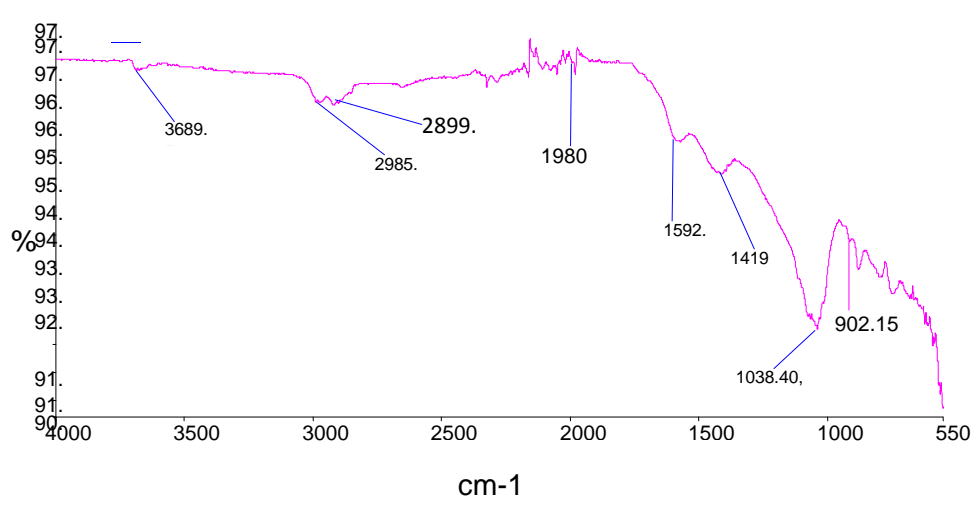

Figure 3 FTIR Spectrum of Morupule coal before adsorption

The presence of bands at $3689.5 \mathrm{~cm}^{-1}$ represents the free $\mathrm{OH}$ stretch. The $=\mathrm{C}-\mathrm{H}$ stretch is found at $2985.8 \mathrm{~cm}^{-1}$. The $-\mathrm{C}-\mathrm{H}$ stretching is at $2899.5 \mathrm{~cm}^{-1}$ and bending is at $1419.0 \mathrm{~cm}^{-1}$. Coal also shows bands at $1592.7 \mathrm{~cm}^{-1}$ which are assigned to the $\mathrm{N}-\mathrm{H}$ bending vibration. The presence of the $\mathrm{S}=\mathrm{O}$ bend is confirmed by a peak at $1038.40 \mathrm{~cm}^{-1}$ The $\mathrm{C}=\mathrm{C}$ assymetric strech is found at $902.15 \mathrm{~cm}^{-1}$. The FTIR of the coal after adsorption was not useful as Morupule coal has a complex structure with functional groups that are also characteristic of the dye investigated.

\subsection{Adsorption parameters}

\subsubsection{Effect of concentration on kinetics}

The effect of varying concentration on methyl orange adsorption kinetics was investigated in the concentration range $1.56 \times 10^{-5} \mathrm{M}$ to $1.019 \times 10^{-4} \mathrm{M}$. Figure 4 presents the kinetics data at $299.9 \mathrm{~K}$. Clearly, at all concentrations the process is at equilibrium within two hours, with the higher concentrations taking longer and giving a higher adsorption capacity than the lower concentrations. The adsorption capacities of the three lower concentrations are very low and very close whereas the three higher concentrations are noticeably much higher and not as close.

The process is initially rapid but slows down as it approaches equilibrium adsorption for the various initial concentrations.
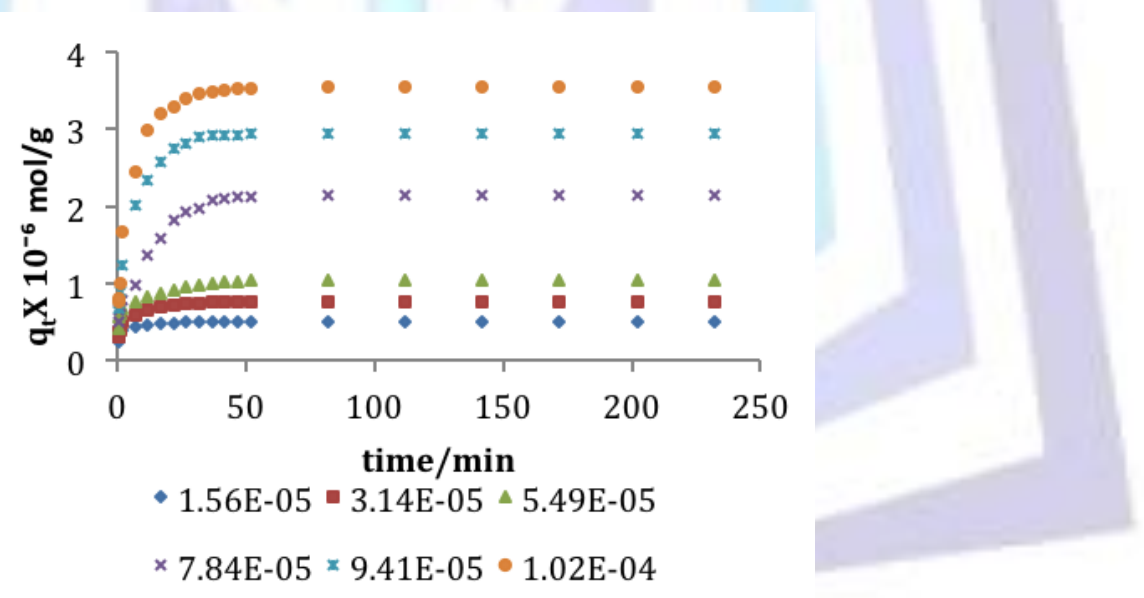

Figure 4 Effect of Concentration on the adsorption of Methyl Orange onto Morupule coal at 298K

The increase in rate with increasing concentration can be attributed to an increase in the driving force or increased concentration gradient as the initial concentration is increased from $1.56 \mathrm{E}-5 \mathrm{M}$ to $1.019 \times 10^{-4} \mathrm{M}$. The initial concentration provides a driving force to overcome the effect of mass transfer resistance to adsorbate (methyl orange) in the aqueous solution and solid adsorbent phase[25, 26]. Figure 4 shows that in most cases, equilibrium was reached within the first 50 minutes but the process was allowed to continue for over three hours. The initial rapid section can be attributed to the initial large numbers of vacant easily accessible adsorption sites at the solid surface. As contact time increases the process slows down as the surface concentration of easily accessible vacant sites decreases; furthermore, there could be a contribution from steric repulsion forces between adsorbed dye molecules as well as with incoming ones.

\subsubsection{Effect of temperatureon kinetics}

Figure 5 shows an increase in the rate and capacity of adsorption of methyl orange as the temperature is raised from $208 \mathrm{~K}$ to $308 \mathrm{~K}$ indicating a dependence upon temperature indicating that the adsorption process is probably activated. However, increasing temperature may cause some swelling effects within the internal structure of Morupule coal creating more sites for more uptake of methyl orange thus falsifying the temperature effect. 


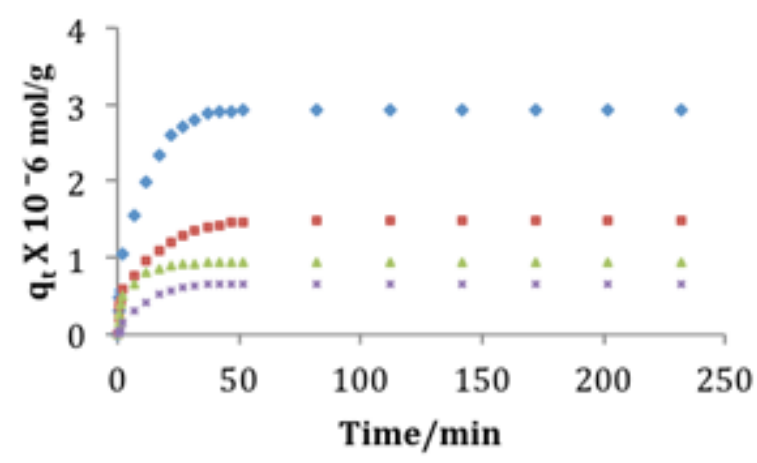

$\cdot 318.95 \quad-308.85 \quad * 298.95 \quad * 288.65$

Figure 5 Effect on temperature increase on the adsorption of Methyl orange onto Morupule coal 3.2.3Effect of $\mathrm{pH}$ on kinetics

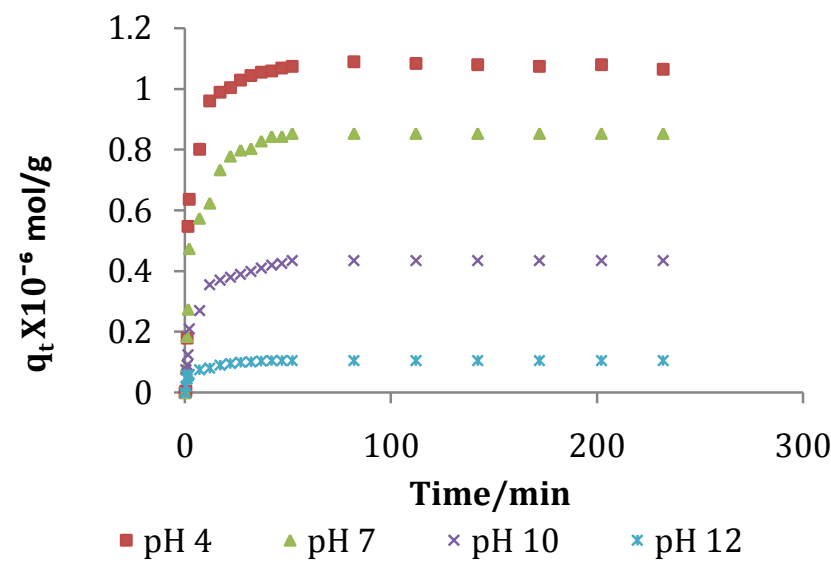

Figure 6 Effect of $\mathrm{pH}$ on the adsorption of Methyl orange onto Morupule coal

From Figure 6, an increase in $\mathrm{pH}$ reduces the adsorption of methyl orange. In acidic media there is high population of hydrogen $\mathrm{H}^{+}$ions. It is thought that adsorption of methyl orange is favoured at lower $\mathrm{pH}$ values as seen figure7, probably because at these $\mathrm{pHs}$, methyl orange assumes the structure shown below in figure 7 .

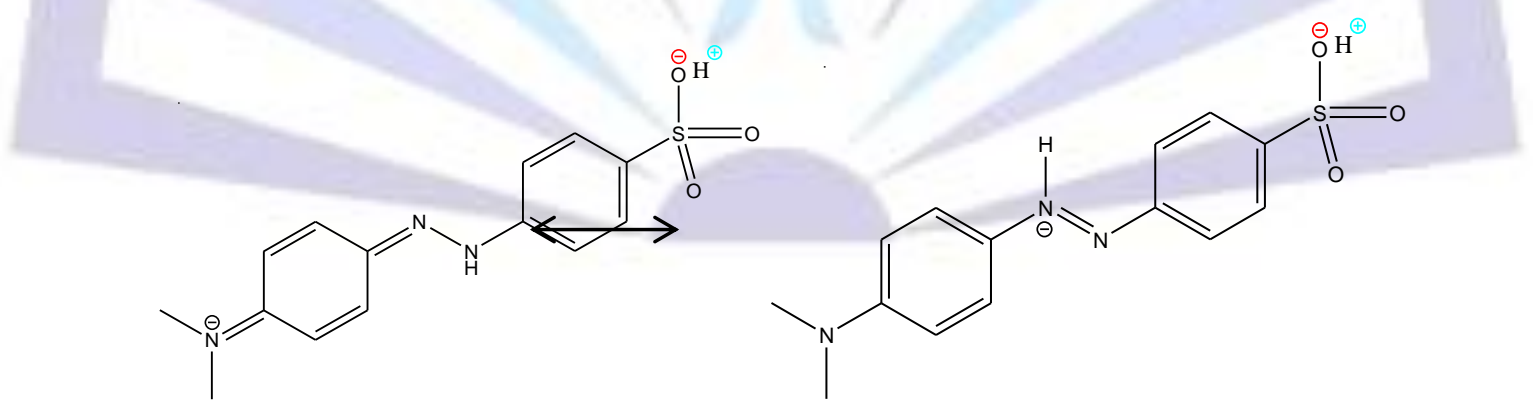

Figure 7 methyl orange at low pH (acid conditions)

As it can be seen, protonation of the tautomer nitrogen atoms gets them involved in conjugated double bond systems that delocalises the positive charge. This is able to interact with the negatively charged surface of Morupule coal, and hence adsorption is increased. 
<smiles>CN(C)c1ccc(/N=N/c2ccc(S(=O)(=O)O)cc2)cc1</smiles>

\section{Figure 8 Methyl orange at higher $\mathrm{pH}$ (basic conditions)}

From figure 8 above, it can be seen that methyl orange exist as an anion at higher $\mathrm{pHs}$ and also $\mathrm{OH}^{-}$ions are abundant in the solution. Consequently there will be repulsion of the dye by the negatively charged surfaces of the adsorbents. Furthermore reduction in adsorption could be due to competitive adsorption between the strong base $\left(\mathrm{OH}^{-}\right)$and the dye anion at higher $\mathrm{pH}$ values.

\subsection{Kinetics' analysis}

\subsubsection{Lagergren Pseudo $1^{\text {st }}$ order Kinetic model}

Lagergren pseudo-first-order rate equation (equation 2 below), the earliest known model describing the adsorption rate based on the adsorption capacity [27], was used to analyse experimental data.

$\log \left(q_{e}-q_{t}\right)=\log q_{e}-\frac{k_{1}}{2.303} t$

Where $k_{1}$ is the pseudo first order rate constant in $\mathrm{g} / \mathrm{mg}^{*} \mathrm{~min}$

$q_{e}$ is the amount adsorbed at equilibrium, $q_{t}$ is the amount adsorbed at time $t$ and $t$ is the time.

A plot of $\log \left(q_{e}-q_{t}\right)$ against $t$ gives a straight line and $k_{1}$ can be determined from the slope and $q_{e}$ from the intercept. The theoretical and the equilibrium amount adsorbed $q_{e}$ can be determined from the plot.

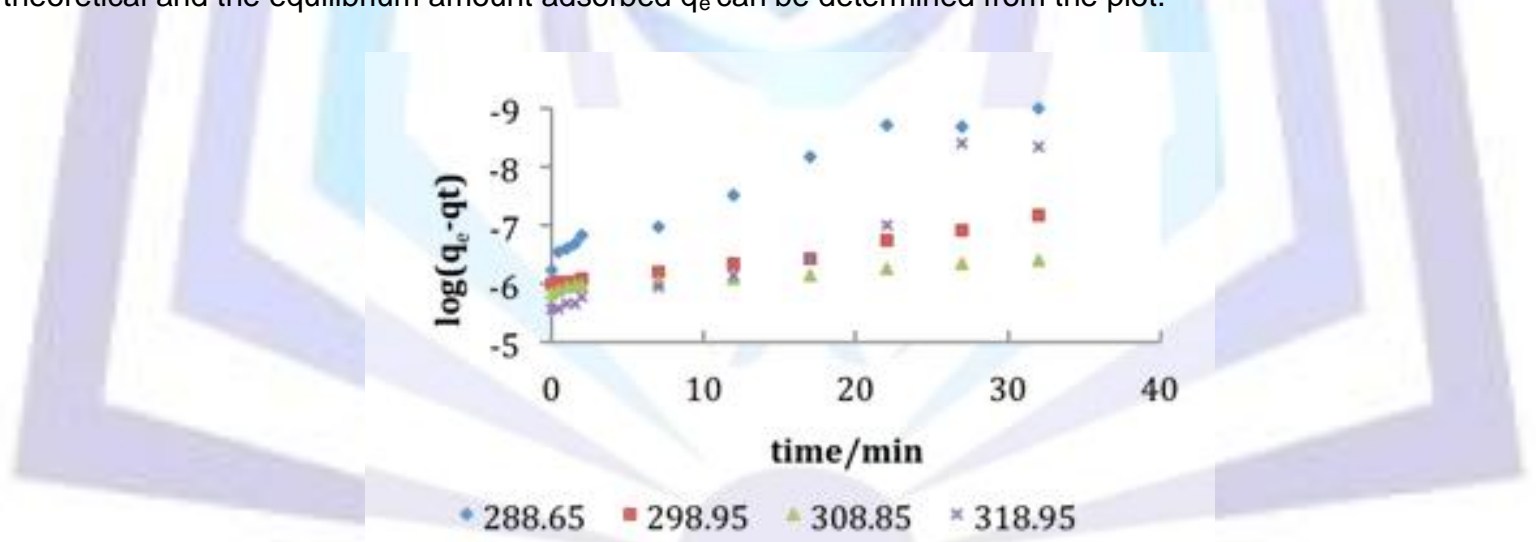

Figure 9 Legergren pseudo first order kinetic model for the adsorption of methyl orange onto morupule coal at various temperatures

Figure 9 above shows that the Lagergren pseudo first fitting gives two straight lines for each of the temperatures in the range $288-318 \mathrm{~K}$ showing that multiple pseudo first order kinetics sorption processes are occurring. Each of the two lines represents a pseudo first order kinetic mechanism [28-30]. The first section can be associated with the binding of methyl orange to the easily accessible surface of the adsorbents, the second section/stage to adsorption of methyl orange onto the less accessible surface. This can be associated with adsorption of the dye molecules after diffusing through a thin layer of the bound dye molecules to reach the available surface [28][31] or due to a gradual swelling of the coal to avail more surface.

From table 1 below, it is observed that the theoretical amount adsorbed $q_{e}$ cal significantly differs from the experimentally determined amount adsorbed $q_{e} \exp$. The $x^{2}$ values, which measure the difference between the model data and the experimental data, are very large, indicating that the adsorption process cannot be described using the Lagergren pseudo first order model. This is also supported by the low $R^{2}$ values for this model as seen from table 1 . 
Table 1Lagergren pseudo first order model parameters

\begin{tabular}{|l|l|l|l|l|}
\hline Parameter & \multicolumn{4}{|l|}{ Morupule coal } \\
\hline $\begin{array}{l}\text { Temp(K), pH } \\
\text { 7.16, 5.488E - } \\
\mathbf{5 M}\end{array}$ & $\mathrm{K}_{\mathbf{1}} / \mathbf{m i n}$ & $\begin{array}{l}\mathbf{Q}_{\mathbf{e}} \mathbf{E - 7} \\
\mathbf{\text { mol} / \mathbf { g }}\end{array}$ & $\begin{array}{l}\mathbf{Q}_{\text {ecal }} \\
\text { E-7 } \\
\mathbf{~ m o l} / \mathbf{g}\end{array}$ & $\mathbf{R}_{\mathbf{1}}$ \\
\hline 288.65 & 0.199 & 6.00 & 35.71 & 0.9669 \\
\hline 298.95 & 0.136 & 9.68 & 13.35 & 0.7515 \\
\hline 308.85 & 0.0398 & 15.30 & 18.02 & 0.9865 \\
\hline 318.95 & 0.199 & 27.09 & 3.12 & 0.9154 \\
\hline$X^{2}$ & $21.027 \times 10^{-6}$ & & \\
\hline
\end{tabular}

\subsubsection{Lagergren pseudo $2^{\text {nd }}$ order model}

The pseudo-second-order rate expression (equation 3) has been widely applied to the adsorption of pollutants from aqueous solutions [20],27, 32, 33].

$\frac{t}{q_{t}}=\frac{1}{k_{2} q_{e}^{2}}+\frac{1}{q_{e}} t$

A plot of $\frac{t}{q_{t}}$ against $\mathrm{t}$ gives a straight line from which $k_{2}$ and the theoretical equilibrium amount adsorbed can be determined. Here $k_{2}$ is the pseudo first order rate constant in $\mathrm{mol} / \mathrm{g} \mathrm{min}$.

$q_{e}$ is the amount adsorbed at equilibrium, $q_{t}$ is the amount adsorbed at time $\mathrm{t}, \mathrm{t}$ is the adsorption time,

$k_{2} q_{e}^{2}=\mathrm{h}$, gives the initial adsorption rate ( $\left.\mathrm{mol} / \mathrm{g} \mathrm{min}\right)$.

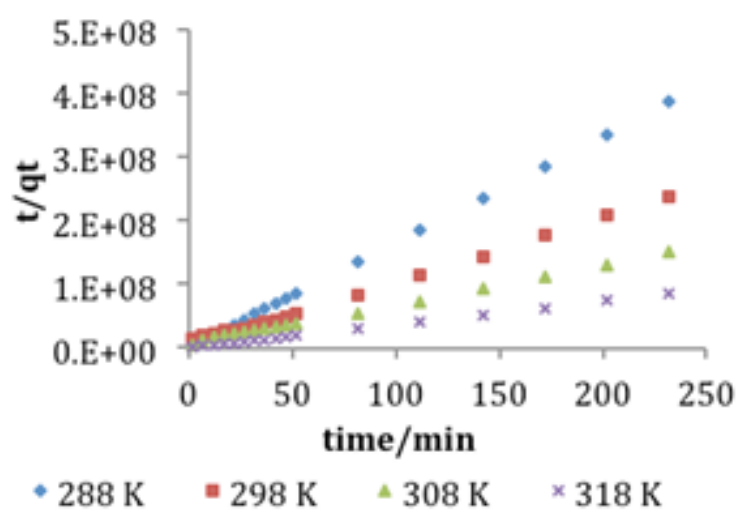

Figure 10 Lagergren pseudo second order model for the adsorption of methyl orange onto morupule coal at different temperatures

Figure 10 above shows that the entire range of experimental data fits the Lagergren pseudo second order model very well at all the temperatures indicating that pseudo second order kinetics is in operation and that the rate determining step in the methyl orange adsorption onto Morupule coal involves a three body collision mechanism. The constant $\mathrm{h}, q_{e}$ cal and $\mathrm{x}^{2}$ were calculated and are shown in table 2 together with the regression coefficient $R^{2}$.

Table 2 clearly shows that $q_{e}$ cal and $q_{e}$ exp are in close agreement, and the $\mathrm{x}^{2}$ values for this model are very low confirming that Morupule coal follows the Lagergren Pseudo second order model. Furthermore, the correlation coefficients are higher than those of the Lagergren pseudo first ordermodel [34-38].From table 2 below, the lagergren pseudo second order rate constant $\mathrm{k}_{2}$ no clear trend as temperature is increased from $(288-318) \mathrm{k}$. 
Table 2Lagergren pseudo second order parameters

\begin{tabular}{|c|c|c|c|c|c|}
\hline \multirow{2}{*}{$\begin{array}{l}\text { Parameter } \\
\text { Temp(K), } \\
\text { pH7.16, } \\
5.488 \\
\text { E -5M }\end{array}$} & \multicolumn{4}{|c|}{ Morupule coal } & \multirow[b]{2}{*}{$\begin{array}{l}\text { h } \\
\text { (mol/ } \\
\text { g/min } \\
\text { ) } \\
\text { E-6 }\end{array}$} \\
\hline & $\begin{array}{l}\mathbf{k}_{2} \\
(\mathrm{~mol} / \mathrm{g} / \\
\mathrm{min}) \\
\mathrm{E6}\end{array}$ & $\begin{array}{l}\mathrm{Qe}_{\mathrm{e}} \\
\mathrm{xp} \\
\mathrm{E}-7 \\
\mathrm{~mol} \\
/ \mathrm{g}\end{array}$ & $\begin{array}{l}\mathbf{Q e}_{\text {cal }} \\
\mathrm{E}-7 \\
\mathrm{~mol} / \mathrm{g}\end{array}$ & $\mathbf{R}^{2}{ }_{2}$ & \\
\hline 288.65 & 6.6720 & $\begin{array}{l}6.00 \\
0\end{array}$ & 5.00 & 1.000 & 1.668 \\
\hline 298.95 & 0.1392 & 9.68 & 10.13 & $\begin{array}{l}0.997 \\
0\end{array}$ & 0.142 \\
\hline 308.85 & 0.0460 & $\begin{array}{l}15.3 \\
0\end{array}$ & 16.36 & $\begin{array}{l}0.998 \\
0\end{array}$ & 0.123 \\
\hline 318.95 & 0.1973 & $\begin{array}{l}27.0 \\
9\end{array}$ & 27.37 & $\begin{array}{l}0.999 \\
5\end{array}$ & 1.478 \\
\hline$x^{2}$ & \multicolumn{5}{|c|}{$0.007308 \mathrm{E}-6$} \\
\hline
\end{tabular}

Similar results were obtained in the study of bio sorption of yellow 4GL on to kaolinite [1], methylene blue and Congo red on to Activated carbon[39], humic and tannic acid on to chitosan [40], and methyl orange onto Calcined lampindo volcanic $\operatorname{mud}[41]$.

\subsubsection{Intra particle diffusion model}

This model holds for adsorbents with porous surfaces and in these, the intra particle diffusion across the double layer will be the 'rate determining' step. This model is characterised by 3 consecutive steps.

1. Transport of sorbate from the bulk solution to outer surface of the sorbent by molecular diffusion, known as film diffusion.

2. The transport of sorbate from the particle surface to the interior surfaces, known as internal diffusion.

3. Then the last step involves adsorption of solute particles from the active sites onto the interior surfaces of the pores.

Waber and Morris derived a relationship (equation 4) for this model from which the constant $k_{i}$ and $q_{t}$ can be derived

$$
q_{t}=k_{i} t^{0.5}+C
$$

Where $q_{t}$ is the amount, $k_{i}$ is the intra particle diffusion constant in $\mathrm{mg} \cdot \mathrm{gmin} 0.5$ under initial rates, $\mathrm{C}$ is a constant

A plot of $q_{t}$ against $t^{0.5}$ should give a graph of two parts, the linear, second part which is due to intra particle diffusion and the straight portion is due to boundary layer diffusion effects.

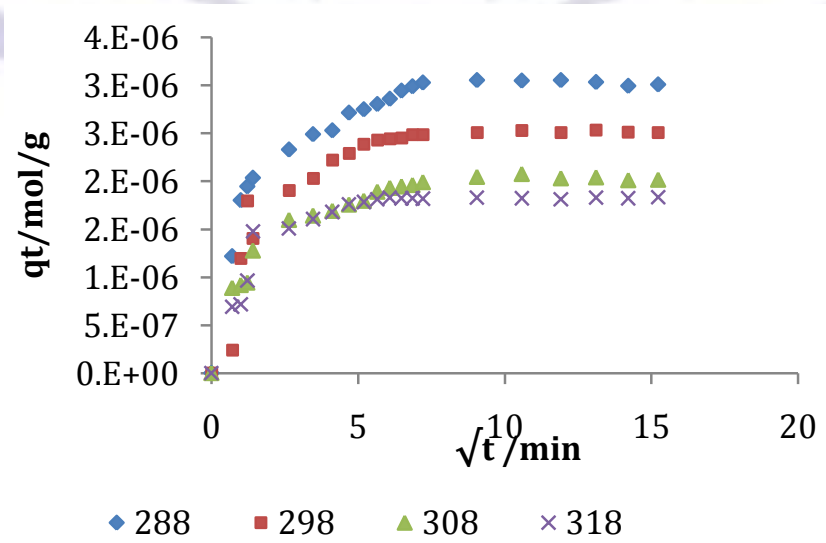

Figure 11 Intra particle Diffusion plot for the adsorption of Methyl orange onto Morupule coal

Figure 11, shows that the intra particle diffusion model fitted from 6 minutes of the adsorption process indicating that the surface of coal was easily available for the first 6 minutes of the process. This is expected, since there is no double layer 
as $\mathrm{MO}$ is a salt. After this, the oncoming methyl orange molecules had to diffuse through the formed layer of adsorbed molecules to reach the surface of the adsorbent resulting in the presence of surface diffusion, which became more noticeable at higher temperatures $\left(\mathrm{K}_{\mathrm{i}}\right.$ increases with temperature as shown in table 3$)$ due to increment in thermal energy $[15,42]$

Table 3Intra particle diffusion model parameters

\begin{tabular}{|c|c|c|c|}
\hline Parameter & \multicolumn{3}{|c|}{} \\
\hline $\begin{array}{c}\text { Temperature( K), } \\
\text { pH 7.16, 5.488E - } \\
\mathbf{5 M}\end{array}$ & $\begin{array}{c}\mathbf{k}_{\mathbf{i}} \\
\mathbf{m o l \cdot g} \sqrt{ }{ }^{\text {min }} \\
\mathbf{E - 8}\end{array}$ & $\mathbf{R}_{\mathbf{i}}{ }^{2}$ & $\begin{array}{c}\text { Intercept } \\
\mathbf{E - 7}\end{array}$ \\
\hline 288 & 3.00 & 0.830 & 4.0 \\
\hline 298 & 20.00 & 0.9846 & 1.0 \\
\hline 308 & 20.00 & 0.9773 & 1.0 \\
\hline 318 & 70.00 & 0.945 & 6.0 \\
\hline
\end{tabular}

\subsection{Thermodynamics' analysis and adsorption isotherms}

Interaction of adsorbate with adsorbents was investigated by plotting adsorption isotherms. In the current case equilibrium adsorption is plotted against equilibrium concentration at constant temperature. The data obtained was then fitted on various models to obtain a comprehensive understanding of the nature of the interactions involved.

\subsubsection{Temkin model}

Temkin and Pyzhev's adsorption model based on the effect of indirect adsorbent -dye interactions on adsorption leads to, the heat of adsorption of all the molecules in a layer decreasing linearly with surface coverage.

The quantity adsorbed at equilibrium $\mathrm{q}_{e}$ is related to equilibrium concentration $\mathrm{c}_{\mathrm{e}}$ by equation 5 below, which linearizes to equation 6 below. A plot of $q_{e}$ against $\ln C_{e}$ gives the heat of adsorption from the slope and the equilibrium-binding constant from the intercept. A small value of the parameter b model indicates a physisorption process.

$q e=\frac{R T}{b} \ln \epsilon_{e}+\left(\frac{R T}{b}\right) \operatorname{lnc} c_{e}$

$$
B=\frac{R T}{b}
$$

Equation 5 above transforms into equation 6 below, the plottable tempkin model isotherm equation.

$$
q e=B \ln A+B \ln c_{e}
$$

Where

$A=K_{t}$ is the Temkin Isotherm equilibrium binding constant in $L / g$ which corresponds to maximum binding energies,

$\mathrm{b}$ is the Temkin isotherm constant giving heat of adsorption $\mathrm{J} / \mathrm{mol}, \mathrm{R}$ is the universal gas constant $(8.314 \mathrm{~J} / \mathrm{mol} \cdot \mathrm{K}$.

$\mathrm{T}$ is temperature in Kelvin

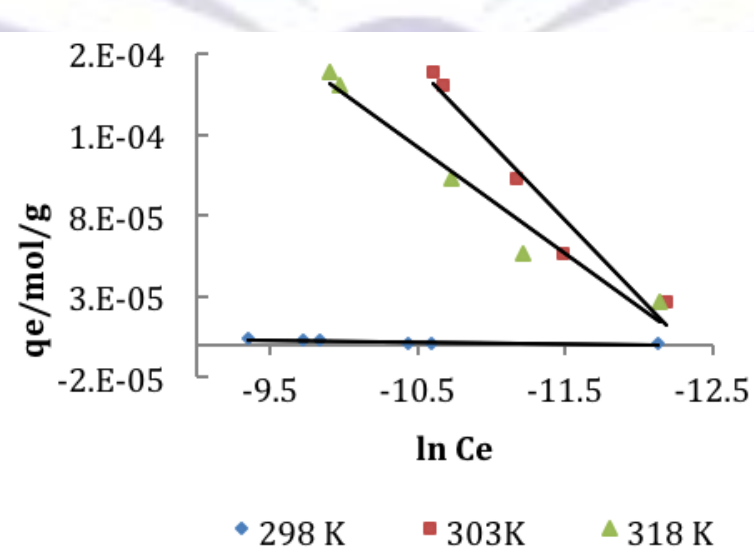

Figure 12 tempkin model plot for the adsorption of methyl orange onto morupule coal.

The experimental data fitted the Temkin model very well for all temperatures in the range investigated. However, the equilibrium binding constant shows no clear trend as temperature increases. 
Table 4Temkin model parameters

\begin{tabular}{|c|c|c|c|c|}
\hline Temp K & \multicolumn{4}{|l|}{} \\
\hline & $\mathbf{K}_{\mathbf{t}} \mathbf{L} / \mathbf{g}$ & $\mathbf{K}_{\mathbf{t}}$ E4 L/g & $\begin{array}{c}\text { B E6 } \\
\mathbf{J} / \mathbf{m o l}\end{array}$ & $\mathbf{R}^{2}$ \\
\hline 298 & $1.1028 \mathrm{E} 5$ & 5.8498 & 104.98 & 0.946 \\
\hline 300 & $\begin{array}{c}1.3594 \mathrm{E} \\
20\end{array}$ & 22.979 & 3.0566 & 0.963 \\
\hline 318 & 0.009705 & 21.627 & 2.1850 & 0.982 \\
\hline
\end{tabular}

Table 4 shows that the heat of adsorption constant $b$ is very small and decreases with increasing temperature indicating that 'physisorption' was taking place [[38, 43, 44].]

\subsubsection{Freundlich isotherm}

Data was analysed by using an equation established by Freundlich (1906) relating the equilibrium amount adsorbed $\mathrm{q}_{\mathrm{e}}$ with the equilibrium concentration $\mathrm{C}_{\mathrm{e}}$ based on a heterogeneous surface of adsorbents thus:

$\ln q_{e}=\ln K_{f}+\frac{1}{n} \ln c_{e}$

Where $q_{e}$ is the amount adsorbed per unit mass, $C_{e}$ is the concentration at equilibrium, $1 / \mathrm{n}$ is the Freundlich heterogeneity parameter.A plot of $l n q_{e}$ against $l n c_{e}$ will gives a straight line if the surface of the adsorbent is heterogeneous. The plot yields the constant $K_{f}$ from the intercept and $n$ from the slope.

The smaller the value of $1 / \mathrm{n}$, the greater the heterogeneity of the surface, and the more favourable adsorption is. A larger value of $1 / \mathrm{n}$ indicates that adsorption is unfavourable.

$\mathrm{K}_{\mathrm{f}}$ is the Freundlich constant indicative of relative adsorption capacity of the adsorbent

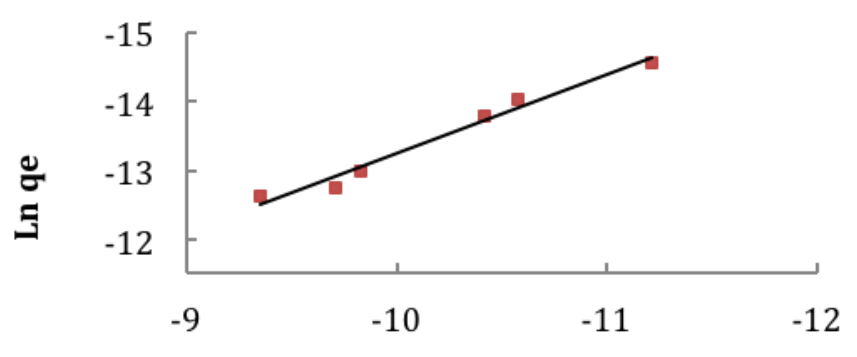

Ln Ce

Figure 13 Freundlich model for the adsorption of methyl orange on to Morupule coal

Table 5Freundlich model parameters

\begin{tabular}{|c|c|c|c|c|}
\hline Adsorbent & Equation & $\mathbf{1 / n}$ & $\mathbf{K}_{\mathbf{f}}$ & $\mathbf{R}^{\mathbf{2}}$ \\
\hline $\begin{array}{c}\text { Morupule } \\
\text { Coal }\end{array}$ & $\begin{array}{c}\mathrm{Y}=1.1372 \mathrm{x}- \\
1.8711\end{array}$ & 1.1372 & 0.1540 & 0.97651 \\
\hline
\end{tabular}

Table 5 was obtained from figure 13 above which clearly shows that the experimental data fits the Freundlich model reasonably well since the correlation coefficients $R^{2}>0.96$. The low value of $K_{f}(0.1540)$ obtained indicates that Morupule coal has a low adsoption capacity[45, 46]. The value of $1 / \mathrm{n}$ of 1.1372 obtained indicates that the coal has a heterogeneous surface and favours the adsorption process [42]. 


\subsection{Thermodynamic parametres}

$\boldsymbol{K}_{\mathbf{0}}=\boldsymbol{V}_{s} \frac{q_{e}}{V_{e}} C_{e}$

8

Where

$q_{e}$ is the surface concentration of dye on adsorbent $\left(\mathrm{mol} \mathrm{g}^{-1}\right), C_{e}$ is the concentration of dye in the equilibrium solution (mol $\left.\mathrm{L}^{-1}\right), V_{s}$ is the activity coefficient of the adsorbed dye, $V_{e}$ is the activity coefficient of the dye in solution. As the concentration of the dye in the solution approaches zero, the activity coefficient approaches unity, and equation 8 above reduces to $K_{0}=\frac{q_{e}}{c_{e}}$ hence

a plot of $\frac{\ln \frac{q_{e}}{c_{e}}}{c_{e}}$ versus $\mathrm{q}_{\mathrm{e}}$ extrapolating $\mathrm{q}_{\mathrm{e}}$ to zero[47, 48]gives an intercept equal to $\ln \mathrm{K}_{\mathrm{o}}$.

$\Delta G^{\circ}=-R T \ln K_{0}$

9

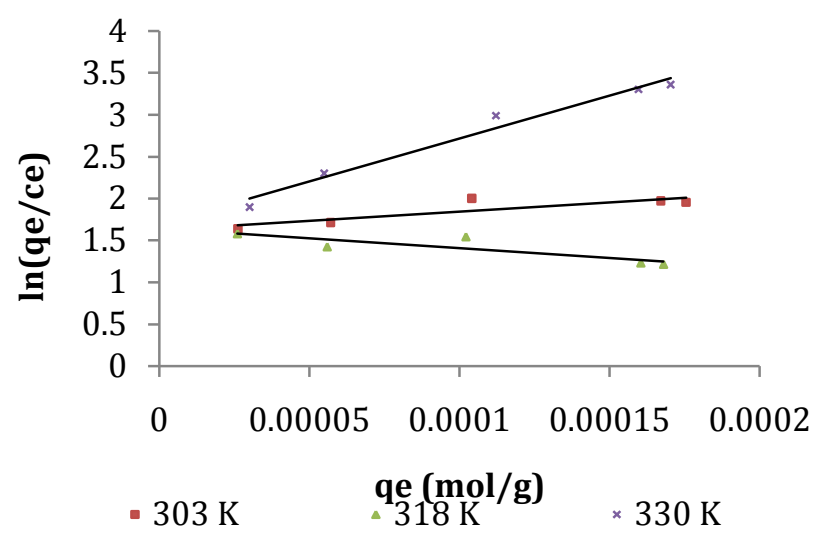

Figure 14 Plot for Determination of $K_{0}$ at different temperature for the adsorption of methyl orange onto morupule coal at various temperatures

Figure 14 above shows that the plot gives straight line. The values of $\mathrm{K}_{\mathrm{o}}$ were determined and are shown in table $6 . \Delta \mathrm{G}^{\circ}$ values were calculated from equation 9above.

Table 6 Thermodynamic parameters for adsorption of Methyl orange onto Morupule coal

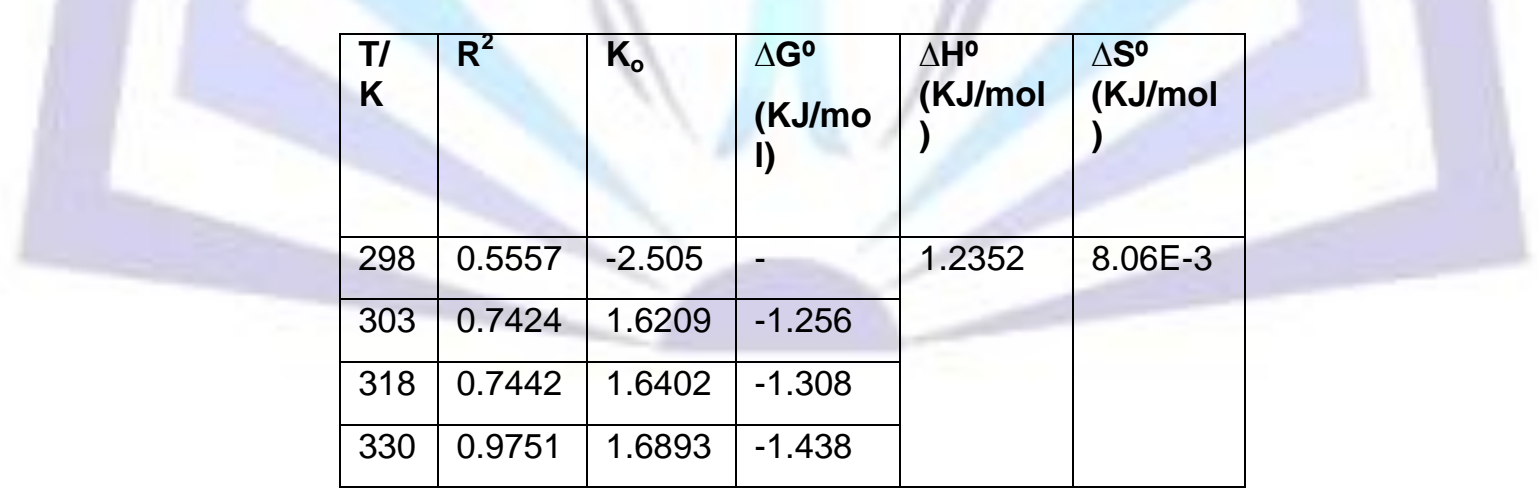

It is clear from table 6 above that $\mathrm{K}_{\mathrm{o}}$ increases with temperature. $\Delta \mathrm{G}^{\circ}$ was calculated using equation 9 and as seen from table 6 above, the values are negative indicating a spontaneous adsorption process [49].

$\Delta \mathrm{H}^{\circ}$ and $\Delta \mathrm{S}^{\circ}$ were determined from the slope and intercept (respectively) of equation 10 below and presented in table 6

$\ln K_{o}=\frac{\Delta S^{0}}{R}-\frac{\Delta H^{0}}{R T}$ 


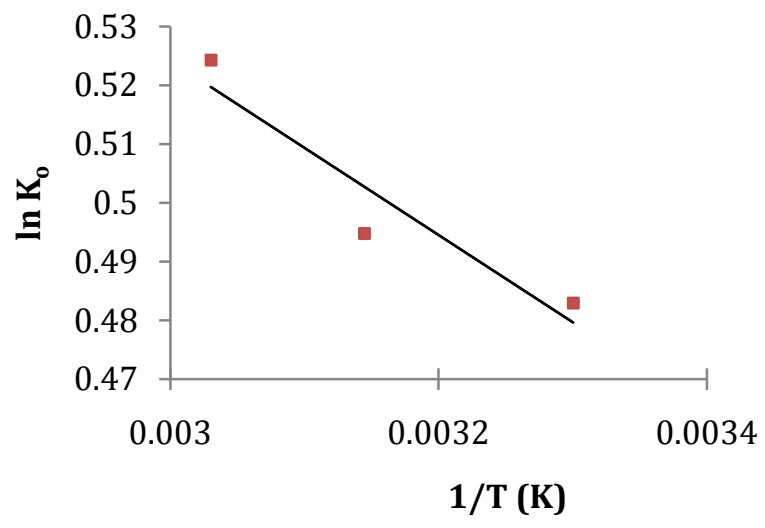

Figure 15 Vant'Hoff plot for the adsorption of methyl orange onto Morupule coal

From figure 15 above, low values of enthalpy and entropy changes accompanying adsorption were obtained. $\Delta \mathrm{H}^{\circ}$ was found to be $1.2352 \mathrm{~kJ} / \mathrm{mol}$ indicating a low affinity of Morupule coal for methyl orange molecules, while $\Delta \mathrm{S}^{\circ}$ was found to be $8.06 \times 10^{-3} \mathrm{~kJ} / \mathrm{mol}$ indicating minimal change in molecular structure and motion [50], confirming physisorption.

\section{CONCLUSIONS}

In this study, it was found that the sorption tends to attain equilibrium in 50 minutes. The adsorption process is best described by the pseudo second-order rate kinetics model probably originating from two simultaneous mechanisms of the same process. Adsorption of $\mathrm{MO}$ on coal increases with increasing temperature, with decreasing $\mathrm{pH}$ and with increasing concentration, in the range studied. The increase of adsorption with increasing temperature was initially thought to be due to activation, in which case chemisorption would be occurring. However, desorption studies showed reversibility and hence ruled out chemisorption. The remaining option is the welknown swelling of the coal associated with increasing temperature which exposes more area for the physisorption process. The latter is supported by the very low enthalpy and entropy changes accompanying adsorption as shown in table 6 Section 3.5. The increase of adsorption with decreasing $\mathrm{pH}$ probably originate from the increased concentration of cationic species resulting from the protonation of the nitrogen atoms in the MO molecule in acid conditions. The protonation leads to double bond conjugation that delocalises the positive charge which interacts with the negatively charged coal surface( figure 8 section 3.2.3). Morupule coal can be used to remove dyes from water however its area needs to be increased to improve its adsorption capacity.

\section{ACKNOWLEDGEMENTS}

The authors gratefully acknowledge the financial contribution from the University of Botswana, Department of Chemistry, and the technical staff in the electron microscopy section in the Department of Physics for their contributions with the electron microscopy.

\section{REFERENCES}

[1]. Dogan, M., M.H. Karaoglu, and M. Alkan, Adsorption kinetics of maxilon yellow $4 G L$ and maxilon red GRL dyes on kaolinite. J Hazard Mater, 2009. 165(1-3): p. 1142-51.

[2]. Nam, S.W., et al., Adsorption characteristics of selected hydrophilic and hydrophobic micropollutants in water using activated carbon. J Hazard Mater, 2014. 270: p. 144-52.

[3]. Gu, X., et al., Adsorption of methyl violet onto mesoporous MCM-48 from aqueous solution. J Nanosci Nanotechnol, 2014. 14(6): p. 4655-63.

[4]. Rioja, N., et al., Competitive removal of pharmaceuticals from environmental waters by adsorption and photocatalytic degradation. Environ Sci Pollut Res Int, 2014.

[5]. Chiban, M., et al., Wastewater treatment by batch adsorption method onto micro-particles of dried Withania frutescens plant as a new adsorbent. J Environ Manage, 2012. 95 Suppl: p. S61-5.

[6]. Kansal, A., N. Siddiqui, and A. Gautam, Wastewater treatment of pulp and paper industry: a review. J Environ Sci Eng, 2011. 53(2): p. 203-18.

[7]. Margot, J., et al., Treatment of micropollutants in municipal wastewater: ozone or powdered activated carbon? Sci Total Environ, 2013. 461-462: p. 480-98.

[8]. Eturki, S., et al., Treatment of rural wastewater by infiltration percolation process using sand-clay fortified by pebbles. Desalination and Water Treatment, 2012. 49(1-3): p. 65-73.

[9]. Guo, J., C. Yang, and G. Zeng, Treatment of swine wastewater using chemically modified zeolite and bioflocculant from activated sludge. Bioresour Technol, 2013. 143: p. 289-97. 
[10]. Badr, N. and K.M. Al-Qahtani, Treatment of wastewater containing arsenic using Rhazya stricta as a new adsorbent. Environ Monit Assess, 2013. 185(12): p. 9669-81.

[11]. Saeed, T., et al., Treatment of tannery wastewater in a pilot-scale hybrid constructed wetland system in Bangladesh. Chemosphere, 2012. 88(9): p. 1065-73.

[12]. Attallah, M.F., I.M. Ahmed, and M.M. Hamed, Treatment of industrial wastewater containing Congo Red and Naphthol Green B using low-cost adsorbent. Environ Sci Pollut Res Int, 2013. 20(2): p. 1106-16.

[13]. Xu, X.H., M.L. Li, and Y. Yuan, Treatment of direct blending dye wastewater and recycling of dye sludge. Molecules, 2012. 17(3): p. 2784-95.

[14]. Ani, Y.B.C., Adsorption studies of dyes using clay-based and activated carbon adsorbents, in Chemical engeneering2004, UNIVERSITI SAINS MALAYSIA: MALAYSIA. p. 162.

[15]. Yu, J.G., et al., Aqueous adsorption and removal of organic contaminants by carbon nanotubes. Sci Total Environ, 2014. 482-483C: p. 241-251.

[16]. Weber, C.T., et al., Removal of hazardous pharmaceutical dyes by adsorption onto papaya seeds. Water Sci Technol, 2014. 70(1): p. 102-7.

[17]. Vasques Ede, C., et al., Modelling studies by adsorption for the removal of sunset yellow azo dye present in effluent from a soft drink plant. Environ Technol, 2014. 35(9-12): p. 1532-40.

[18]. H.M. Pinheiro , E.T., O. Thomas, Aromatic amines from azo dye reduction: status review with emphasis on direct UV spectrophotometric detection in textile industry wastewaters. Journal of dyes and pigments, 2004. 61 p. 121139.

[19]. do Nascimento, G.E., et al., Adsorption of azo dyes using peanut hull and orange peel: a comparative study. Environ Technol, 2014. 35(9-12): p. 1436-53.

[20]. Natasha Tomi, Z.D., Novica Paunovi, Dusan Mijin, Nidad D Radi, Bosko Grbic, Sonja Maskrabi, Bilijana Babi, Danica V Bajuk-Bogdanovi, Nanocrystaline CeO as effective adsorbent of Azo dyes. Langmuir, 2014. 30: $p$. 11582-11590.

[21]. Rego, T.V., et al., Statistical optimization, interaction analysis and desorption studies for the azo dyes adsorption onto chitosan films. J Colloid Interface Sci, 2013. 411: p. 27-33.

[22]. Zhang, L., J.M. Cole, and C. Dai, Variation in optoelectronic properties of azo dye-sensitized TiO2 semiconductor interfaces with different adsorption anchors: carboxylate, sulfonate, hydroxyl and pyridyl groups. ACS Appl Mater Interfaces, 2014. 6(10): p. 7535-46.

[23]. Zhang, X., et al., Removal of azobenzene from water by kaolinite. J Hazard Mater, 2009. 170(2-3): p. 1064-9.

[24]. Brindley, G.W. and G.L. Millhollen, Chemisorption of water at high temperatures on kaolinite: effect on dehydroxylation. Science, 1966. 152(3727): p. 1385-6.

[25]. B.H Hameed, D.K.M., A.L. Ahmad, Equilibrium modeling and kinetic studies on the adsorption of basic dye by a low cost adsorbent: Coconut (Cos nucifera) bunch waste. Journal of hazadous materials, 2008. 158: p. 65-72.

[26]. A. Gurses, C.D., M. Yalcin ,M. Acikyildiz, R. Bayrak, S.Karaca, The adsorption of cationic dye, methylene blue on to clay. Journal of hazadous materials, 2005. B131: p. 217-228.

[27]. Ho, y.-s., Review of second order models for adsorption systems. hazadous material, 2006. B136: p. 681-689.

[28]. Ru-Ling Tseng, F.-C.W., Ruey-Shin Juang Characteristics and Applications of the Lagergren's first order equation for adsorption kinetics. Journal of the institute of Chemical Engineers, 2010. 41: p. 661-669.

[29]. Y.S. Ho , G.M., Pseudo Second order model for sorption processes. Journal of Process Biochemistry, 1998. 34: p. 451-465.

[30]. Y.S. Ho , G.M., A Comparison of Chemisorption kinetic models applied to pollutant removal on various sorbents. Journal of Institute of Chemical engineers, 1998. 76: p. 332-340.

[31]. Sarkar D, C.D., Activation Parameters for kinetics of protein Adsorption at silicawater interface. Journal of colloid interface science, 1993. 157: p. 219-226.

[32]. Komy, Z.R., et al., Kinetic study for copper adsorption onto soil minerals in the absence and presence of humic acid. Chemosphere, 2014. 99: p. 117-24.

[33]. Gholizadeh, A., et al., Kinetic and isotherm studies of adsorption and biosorption processes in the removal of phenolic compounds from aqueous solutions: comparative study. J Environ Health Sci Eng, 2013. 11(1): p. 29.

[34]. Asuha, S., X.G. Zhou, and S. Zhao, Adsorption of methyl orange and Cr(VI) on mesoporous TiO2 prepared by hydrothermal method. Journal of Hazardous Materials, 2010. 181(1-3): p. 204-210. 
[35]. Visa, M., A. Enesca, and A. Duta, Simultaneous Adsorption of Methyl Orange and Heavy Metals from Solution Using Fly Ash. Multi-Functional Materials and Structures li, Pts 1 and 2, 2009. 79-82: p. 247-250.

[36]. Wu, Z.J., et al., Methyl orange adsorption by microporous and mesoporous TiO2-SiO2 and TiO2-SiO2Al2O3 composite xerogels. Composite Interfaces, 2004. 11(2): p. 205-212.

[37]. Li, Y.K., et al., Kinetic Study of Methyl Orange Adsorption from Solution by IOCZ. Advances in Applied Materials and Electronics Engineering li, 2013. 684: p. 194-197.

[38]. Ma, Q.L., et al., Studies on the adsorption behavior of methyl orange from dye wastewater onto activated clay. Desalination and Water Treatment, 2013. 51(19-21): p. 3700-3709.

[39]. Szlachta, M. and P. Wojtowicz, Adsorption of methylene blue and Congo red from aqueous solution by activated carbon and carbon nanotubes. Water Sci Technol, 2013. 68(10): p. 2240-8.

[40]. min-yun Chang, R.-S.J., Adsorption of tannic acid, humic acid,and dyes from water using the composite of chitosan and activated clay. Journal of colloid and interface science, 2004. 278: p. 18-25.

[41]. Jalil, A.A., et al., Adsorption of methyl orange from aqueous solution onto calcined Lapindo volcanic mud. J Hazard Mater, 2010. 181(1-3): p. 755-62.

[42]. Peng Liu, L.Z., Adsorption of dyes from aqueous solutions or suspensions with clay nano-adsorbents. Journal of separation purification technology, 2007. 58: p. 32-39.

[43]. Chen, S.H., et al., Equilibrium and kinetic studies of methyl orange and methyl violet adsorption on activated carbon derived from Phragmites australis. Desalination, 2010. 252(1-3): p. 149-156.

[44]. Ai, L.H., C.Y. Zhang, and L.Y. Meng, Adsorption of Methyl Orange from Aqueous Solution on Hydrothermal Synthesized Mg-Al Layered Double Hydroxide. Journal of Chemical and Engineering Data, 2011. 56(11): p. 4217-4225.

[45]. Yao, Y.J., et al., Equilibrium and kinetic studies of methyl orange adsorption on multiwalled carbon nanotubes. Chemical Engineering Journal, 2011. 170(1): p. 82-89.

[46]. Mittal, A., et al., Studies on the adsorption kinetics and isotherms for the removal and recovery of Methyl Orange from wastewaters using waste materials. Journal of Hazardous Materials, 2007. 148(1-2): p. 229-240.

[47]. M Sekar , V.S., S Rengaraj, Kinetics and equillibrium adsorption study of lead(II) onto activated carbon prepared from coconut shell. Journal of colloid and interface science 2004. 279: p. 307-313.

[48]. Hardijeet K. Boparai, M.J., Denis M.O'Carroll, Kinetics and thermodynamics of Cadmium ion removal by adsorption onto nano zerovalent iron particles. Journal of Hazardous materials, 2010. 2010.11.029: p. 8.

[49]. R, C., Adsorption of organic-chemicals in soils Journal of environmental health, 1989. 83: p. 145-177.

[50]. Adam F, C.J.H., The adsorption of Palmytic acid on rice husk ash chemically modified with Al(iii) ion using the sol-gel technique. journal ofcolloid interface science, 2004. 280: p. 55-61. 